\title{
Ação antioxidante de pigmentos naturais em filés de tilápia do Nilo defumados
}

\author{
Antioxidant action of natural pigments in smoked Nile tilapia fillets \\ Acción antioxidante de los pigmentos naturales en filetes de tilapia del Nilo ahumados
}

\section{Resumo}

O emprego de tecnologias tradicionais e/ou emergentes são fundamentais para a agregação de valor ao pescado, bem como a utilização de produtos naturais que promovam mais de um benefício aos produtos elaborados. Este estudo avaliou o uso de pigmentos naturais com efeito antioxidante na defumação de filés de tilápia, caracterizando o rendimento, composição centesimal, colorimetria, oxidação lipídica e perfil sensorial. Filés de tilápia foram imersos em salmoura $(20 \%+0,5 \%$ de extrato de alecrim) contendo 1,5\% de açaí, açafrão e beterraba em pó, além de um tratamento controle, ausente de corante, por 20 minutos. Os filés foram drenados, desidratados e submetidos ao processo de defumação por 90 minutos. Foram pesados a cada 30 minutos para avaliar as perdas ocorridas pelo processo. As perdas ocorridas variaram de 24,13 a $32,86 \%$ durante o processo. Observou-se uma menor umidade nos filés do tratamento controle. A inclusão dos corantes de açaí e beterraba proporcionaram maior teor de lipídeos nos filés defumados, enquanto o açaí proporcionou menor teor de cinzas. Os filés com utilização da beterraba e açafrão apresentaram maior intensidade de cor e maior preferência pelos avaliadores na análise sensorial. A análise de substâncias reativas ao ácido 
tiobarbitúrico indicou estabilidade da porção lipídica para todos os tratamentos até os 30 dias de estocagem. Portanto, o uso de pigmentos naturais com ação antioxidante, além de promover melhor aceitação do produto por meio de melhoria da aparência, também garante estabilidade oxidativa para maior tempo de armazenamento, demonstrando uma forma de agregação de valor ao pescado.

Palavras-chave: Agregação de valor; Composição química; Oreochromis niloticus; Oxidação lipídica.

\begin{abstract}
The use of traditional and/or emerging technologies are fundamental for adding value to fish, as well as the use of natural products that promote more than one benefit to the elaborated products. This study evaluated the use of natural pigments with antioxidant effect in the smoking of tilapia fillets, characterizing the yield, proximate composition, colorimetry, lipid oxidation and sensory profile. Tilapia fillets were immersed in brine $(20 \%+0.5 \%$ rosemary extract $)$ containing $1.5 \%$ açaí, saffron and beet powder, in addition to a control treatment, without dye, for 20 minutes. The fillets were drained, dehydrated and subjected to a smoking process for 90 minutes. They were weighed every 30 minutes to assess the losses caused by the process. Losses ranged from 24.13 to $32.86 \%$ during the process. It was observed a lower moisture in the fillets of the control treatment. The inclusion of açaí and beetroot dyes provided a higher lipid content in the smoked fillets, while açaí provided a lower ash content. The fillets using beetroot and saffron showed greater color intensity and greater preference by evaluators in the sensory analysis. The analysis of thiobarbituric acid reactive substances indicated stability of the lipid portion for all treatments up to 30 days of storage. Therefore, the use of natural pigments with antioxidant action, in addition to promoting better product acceptance through improved appearance, also ensures oxidative stability for longer storage time, demonstrating a way of adding value to the fish.
\end{abstract}

Keywords: Adding value; Chemical composition; Oreochromis niloticus; Lipid oxidation.

\title{
Resumen
}

El uso de tecnologías tradicionales y / o emergentes son fundamentales para agregar valor al pescado, así como el uso de productos naturales que promuevan más de un beneficio a los productos elaborados. Este estudio evaluó el uso de pigmentos naturales con efecto antioxidante en el ahumado de filetes de tilapia, caracterizando el rendimiento, composición próxima, colorimetría, oxidación lipídica y perfil sensorial. Los filetes de tilapia se sumergieron en salmuera $(20 \%+0.5 \%$ extracto de romero) conteniendo $1.5 \%$ de açaí, azafrán y remolacha en polvo, además de un tratamiento control, sin colorante, durante 20 minutos. Los filetes se escurrieron, se deshidrataron y se sometieron a un proceso de ahumado durante 90 minutos. Se pesaron cada 30 minutos para evaluar las pérdidas ocasionadas por el proceso. Las pérdidas ocurridas oscilaron entre 24,13 y 32,86\% durante el proceso. Se observó una menor humedad en los filetes del tratamiento control. La inclusión de colorantes de açaí y remolacha proporcionó un mayor contenido de lípidos en los filetes ahumados, mientras que el açaí proporcionó un menor contenido de cenizas. Los filetes con remolacha y azafrán mostraron mayor intensidad de color y mayor preferencia por parte de los evaluadores en el análisis sensorial. El análisis de sustancias reactivas al ácido tiobarbitúrico indicó la estabilidad de la porción lipídica para todos los tratamientos hasta 30 días de almacenamiento. Por lo tanto, el uso de pigmentos naturales con acción antioxidante, además de promover una mejor aceptación del producto a través de una apariencia mejorada, también asegura la estabilidad oxidativa para un mayor tiempo de almacenamiento, demostrando una forma de agregar valor al pescado. Palabras clave: Composición química; Oreochromis niloticus; Oxidación de lípidos; Valor agregado.

\section{Introdução}

Com o crescimento populacional mundial surge a demanda crescente por alimentos, principalmente os que apresentam elevado valor biológico (FAO, 2018) e dentre eles o peixe é de grande importância. O pescado tem potencial para fornecer nutrientes à população, em função da qualidade nutricional desse alimento, considerado como padrão nutricional pela FAO (Justen et al., 2017; Galvão \& Oetterer, 2014). Entretanto, o pescado é altamente susceptível à deterioração, principalmente devido à sua elevada atividade de água, $\mathrm{pH}$ próximo a neutralidade e ácidos graxos insaturados de fácil oxidação, principalmente os poli-insaturados, que representam condições ótimas para crescimento de microrganismos ou oxidação da porção lipídica (Tilami \& Sampels, 2018).

Diversas tecnologias são empregadas no processamento do pescado visando a conservação a fim de adiar/retardar as reações que acontecem nesse tipo de produto promovendo uma maior vida de prateleira (Gonçalves, 2011). Aliado a essas tecnologias, o uso de aditivos que venham a realçar características sensoriais ou que promovam maior tempo de prateleira são empregados nos produtos alimentícios como forma de agregar valor, pois conforme Franco (2003), quanto mais se emprega tecnologias, maior é o valor agregado ao produto.

Nesse contexto, se enquadra o processo de defumação, que além de promover a conservação do produto por meio da 
diminuição da atividade de água e ação dos compostos da fumaça que evita a ação microbiológica, também realça aspectos organolépticos como sabor, cor, odor e textura (Assis et al., 2009). O processo contribui, além da ação antibacteriana, como fungicida e possui ação antioxidante em função dos compostos fenólicos presentes na fumaça gerada e o fluxo de fumaça sobre o produto (Franco et al., 2010; Franco et al., 2013).

Alguns estudos foram desenvolvidos com adição de extratos naturais em peixes defumados para avaliar a qualidade do produto, como o trabalho de Jensen (1998) que avaliou o uso de astaxantina com efeito de cor e ação antioxidante em trutas defumadas. Franco et al. (2013) avaliaram a pigmentação com extrato de urucum em filés de tilápia defumados. Vanz (2013) e Santos et al. (2007) utilizaram o extrato de alecrim como antioxidante em filés de tilápia defumados. Sendo assim, torna-se evidente que a adição de extratos naturais com conhecida ação antioxidante no processo de defumação é capaz de proporcionar uma diminuição da oxidação lipídica, além de impactar positivamente nas características físico-químicas e sensoriais do produto final.

Dessa forma, o presente estudo teve por objetivo avaliar o uso de pigmentos naturais com efeito antioxidante na defumação de filés de tilápia, caracterizando estes filés quanto ao rendimento, composição centesimal, colorimetria, oxidação lipídica e perfil sensorial.

\section{Metodologia}

O experimento foi realizado no Laboratório de Tecnologia do Pescado do Departamento de Zootecnia da Universidade Estadual de Maringá, localizado na Fazenda Experimental de Iguatemi - FEI, Iguatemi-PR.

\section{Delineamento experimental}

Este estudo pode ser caracterizado como experimental (Pereira et al., 2018). Foi conduzido em delineamento inteiramente casualizado, avaliando três pigmentos adicionados na salmoura pré-defumação (açaí em pó, açafrão em pó, beterraba em pó), mais um tratamento controle (sem adição de pigmentos), totalizando assim quatro tratamentos, com seis repetições por tratamento, sendo o filé considerado a unidade experimental.

\section{Salmouragem e pigmentação dos filés}

Os filés de tilápia foram submetidos ao processo de salga úmida, utilizando uma salmouragem a 20\% na proporção 2:1 (água/peso dos filés) e adicionado 0,5\% de extrato de alecrim como aromatizante para todos os tratamentos (adaptado de Franco et al., 2013).

Associado ao extrato de alecrim para cada tratamento foi adicionado 1,5\% de corante natural em relação ao peso dos filés (Tratamento 1- sem inclusão de corante, controle; Tratamento 2- açaí em pó; Tratamento 3- açafrão em pó e Tratamento 4beterraba em pó). Os filés permaneceram imersos nessa solução por 20 minutos. Decorrido este período, a solução foi drenada e os filés submetidos a secagem parcial em estufa de ar forçado a $50^{\circ} \mathrm{C}$, por 60 minutos.

\section{Processo de defumação dos filés}

Para defumação foi utilizado o método de defumação à quente, cuja temperatura variou de 50 a $90{ }^{\circ} \mathrm{C}$, utilizando um defumador de inox com geração de fumaça externa a câmara de defumação. O combustível utilizado para produzir a fumaça foi serragem de eucalipto rosa (Eucalyptus globulus) e, para manutenção da temperatura, foi utilizado o gás de cozinha.

Os filés foram submetidos à fumaça por 90 minutos (iniciou-se a $60^{\circ} \mathrm{C}$ e finalizou-se a $90^{\circ} \mathrm{C}$ ). Decorrido esse período, os filés foram retirados do defumador para estabilização da temperatura com o ambiente, embalados a vácuo individualmente e armazenadas sob refrigeração $\left(7 \pm 2^{\circ} \mathrm{C}\right)$, até a realização das análises. 
Para avaliação de rendimento e perdas ocorridas na defumação os filés foram pesados antes de serem colocados na câmara de defumação e a cada 30 minutos durante todo o processo, conforme Franco et al. (2013).

\section{Análises microbiológicas}

As análises microbiológicas dos filés pigmentados e defumados foram realizadas no laboratório de Microbiologia e Microscopia de Alimentos do Departamento de Análises Clínicas da Universidade Estadual de Maringá - UEM. Estas, foram realizadas para o número mais provável (NMP) de coliformes a $35^{\circ} \mathrm{C}$ e $45^{\circ} \mathrm{C}$, contagem de Estafilococos coagulase positiva em unidade formadora de colônia (UFC)/grama e de Salmonellas spp, de acordo com a APHA (1992).

\section{Determinação do pH}

$\mathrm{O}$ pH das amostras foi medido utilizando-se $10 \mathrm{~g}$ de amostra diluída e homogeneizada em $100 \mathrm{~mL}$ de água destilada. O homogeneizado foi submetido aos eletrodos do pHmetro (DM 22, Digimed, São Paulo, Brasil), por 5 minutos, procedendo-se a leitura do pH (Instituto Adolfo Lutz, 2005).

\section{Colorimetria}

A cor da superfície das amostras de filés foi avaliada, utilizando o colorímetro portátil CR-400 Konica Minolta's, (configurações: Iluminante D65; $0^{\circ}$ ângulo de visão e 4 auto-average). Foram realizadas três leituras em cada lado da amostra a temperatura ambiente, e os resultados expressos pelos parâmetros $L^{*}$ (que representa a porcentagem de luminosidade, onde preto 0\%, e branco 100\%), a* (componente vermelho-verde) e b* (componente amarelo-azul) pelo sistema de cor CIELAB.

\section{Análise sensorial}

Foi realizada análise sensorial dos filés defumados, sendo que as amostras foram identificadas com 3 números de forma aleatória e oferecidas a 60 avaliadores não-treinados. A metodologia da análise sensorial foi aprovada pelo Comitê Permanente de Ética em Pesquisa com Seres Humanos da Universidade Estadual de Maringá (Protocolo CAAE 42119121.9.0000.0104).

Foram avaliados a cor e aparência ou impressão global utilizando uma escala hedônica de 9 pontos, tendo como os extremos: 1 (desgostei muitíssimo) e 9 (gostei muitíssimo) (Dutcosky, 2013). Também, foi avaliada a intenção de compra utilizando a escala hedônica de 5 pontos, na qual 5 representava a nota máxima "certamente compraria" e 1 representava a nota mínima "certamente não compraria", empregando os procedimentos descritos para análise sensorial por Meilgaard (1999), Damásio e Silva (1996).

\section{Análise da composição centesimal}

Foram realizadas análises de composição centesimal dos filés pigmentados e defumados. Os teores de umidade e cinzas foram determinados de acordo com a metodologia da Association of Official Analytical Chemists (AOAC, 2005). Os teores de proteína bruta foram avaliados pelo método de semi-micro Kjeldahl (Silva \& Queiroz, 2002). A extração dos lipídios foi realizada segundo adaptação do método citado por Bligh \& Dyer (1959) utilizando-se uma mistura de clorofórmio, metanol e água em proporção de 2:2:1,8 (v/v/v), respectivamente.

\section{Determinação da oxidação lipídica}

Para avaliação da oxidação lipídica dos filés pigmentados e defumados, foi observado a oxidação equivalente em malonaldeído, pela metodologia de determinação das substâncias reativas ao ácido tiobarbitúrico (TBARS) de acordo com Juncher et al. (2001). As avaliações foram realizadas nos períodos de 0, 15, e 30 dias após armazenamento dos filés a temperatura 
de refrigeração $\left(7^{\circ} \mathrm{C}\right)$. Para a extração dos aldeídos foram misturadas $5 \mathrm{~g}$ de amostra dos filés pigmentados e defumados já homogeneizada com $15 \mathrm{~mL}$ da solução extratora, e em sequência foi homogeneizada no Ultra Turax, por 1 minuto. Em seguida as amostras foram filtradas e, o filtrado utilizado para análise de TBARS. Na determinação das substâncias reativas ao TBARS, foi transferido uma alíquota de $1,5 \mathrm{~mL}$ do extrato para tubos falcon de $15 \mathrm{~mL}$, e adicionado $1,5 \mathrm{~mL}$ de da solução de ácido tiobarbitúrico, após colocado em banho fervente $\left(100^{\circ} \mathrm{C}\right)$ durante 15 minutos, esfriadas em água gelada durante 5 minutos. As amostras foram transferidas para cubetas e a leitura realizada a 532, 538 e $540 \mathrm{~nm}$, utilizando água destilada como branco. Os resultados foram expressos em $\mathrm{mg}$ MDA/kg de produto.

\section{Análise estatística}

Os dados obtidos nas análises de composição centesimal, colorimetria, $\mathrm{pH}$ e TBARs foram submetidos à análise de variância (ANOVA), e em caso de diferenças significativas $(\mathrm{P}<0,05)$, as médias foram comparadas pelo teste de Tukey, utilizando o software Statistical Analysis System (SAS, 2010).

As análises microbiológicas foram apenas para caracterização do produto elaborado, não sendo aplicada a análise estatística para estes resultados.

\section{Resultados e Discussão}

\section{Perdas ocorridos durante o processo de defumação}

Em geral, a utilização de corantes naturais no preparo de filés destinados a defumação, não influenciaram nas perdas parciais ocasionadas durante o processo de defumação, no entanto quando avaliados os 3 tempos (30, 60 e 90 minutos) as perdas foram maiores aos $60 \mathrm{mim}$ (Figura 1).

Figura 1. Representação gráfica das perdas ocorridas no processo de defumação em filés de tilápia com uso de diferentes corantes naturais.

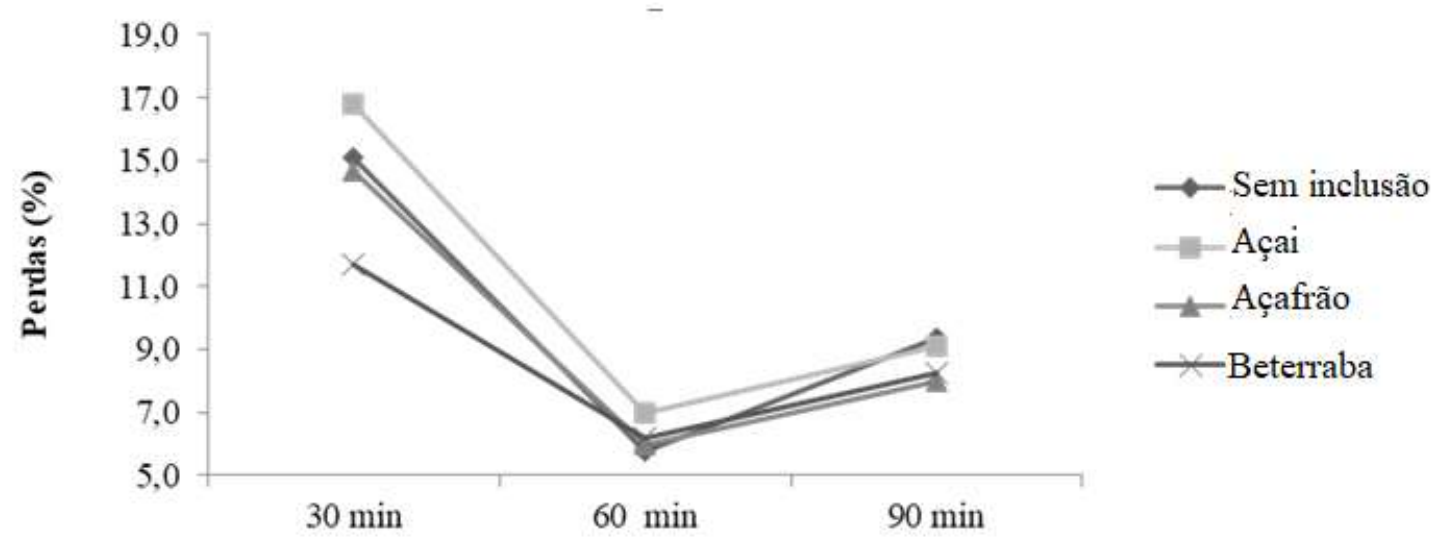

Fonte: Autores (2021).

As perdas totais foram de 30,21\%, 32,86\%, 28,66\% e 24,13\% para o tratamento controle (sem pigmento), açaí, açafrão e beterraba, respectivamente (Figura 1). Os valores encontrados são inferiores aos observados por Santos et al. (2007) para troncos e filés de tilápia defumados, certamente devido ao tempo inferior de exposição à fumaça que neste trabalho foi de apenas 90 minutos, enquanto Santos et al. (2007) utilizaram 4 horas exposição das tilápias (tronco e filé) à fumaça. Franco et al. (2010) também utilizaram maior tempo de exposição à fumaça, mas atribuíram os maiores teores de perdas ao método de defumação, sendo a quente superior ao a frio. 


\section{Análises microbiológicas}

A análise microbiológica dos filés de tilápia pigmentados e defumados apresentaram resultados dentro dos padrões microbiológicos estabelecidos pela legislação (Brasil, 2019). Cujos valores, para coliformes a $35{ }^{\circ} \mathrm{C}$ e $45{ }^{\circ} \mathrm{C}$ foi $<3 \mathrm{NMP} / \mathrm{g}$, Estafilococos coagulase positiva foi $<10^{2}$ e não se constatou presença de Salmonella ssp em $25 \mathrm{~g}$ de amostra.

pH

Não houve diferença de $\mathrm{pH}$ entre os filés defumados com diferentes pigmentos naturais, cujos valores variaram entre 5,8 a 6,0 para os tratamentos (Figura 2). Contudo, pode-se observar que com o aumento do tempo de estocagem houve um acréscimo linear desta variável $\left(\mathrm{y}=0,15+0,03 \mathrm{x} ; \mathrm{R}^{2}=91,5 \%\right)$.

Quando comparados com o $\mathrm{pH}$ do filé in natura, constatou-se valores relativamente inferiores para o filé pigmentado e defumado. O filé in natura, apresentou valores médios de $\mathrm{pH}$ mais próximo da neutralidade, inferindo que o processo de defumação tende a acidificar o $\mathrm{pH}$ da carne. Isto é decorrente dos compostos da fumaça, pois como principais componentes estão os ácidos fórmico, acético, butírico, caprílico e vanílico; o dimetoxifenol, metilglioxal, furfural, metanol, etanol, octanol, acetaldeído, diacetil, acetona, 3,4-benzopireno. Entretanto, já foram detectados mais de 200 componentes presente na composição da fumaça gerada pela queima da madeira (Gava, 2008).

Figura 2. Potencial hidrogeniônico $(\mathrm{pH})$ de amostras de filés defumados com diferentes corantes naturais e filé in natura ao longo de 30 dias de armazenamento.

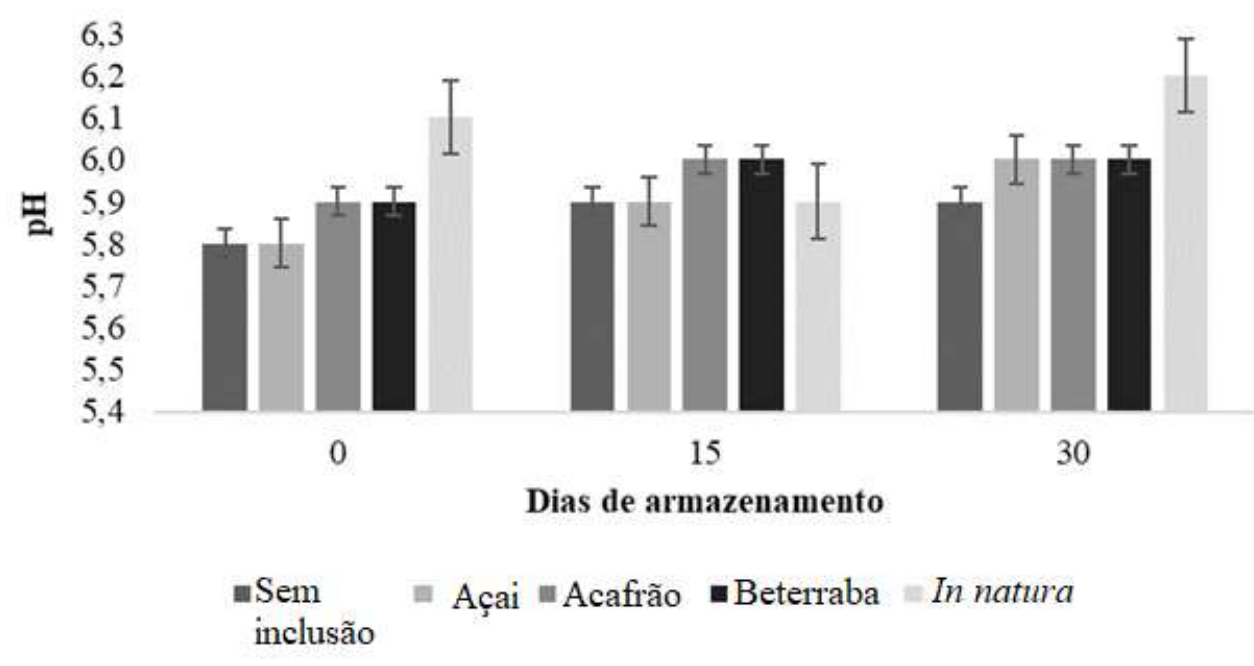

Fonte: Autores (2021).

Avaliando o pH dos filés, foi do in natura que apesentou maior instabilidade durante o armazenamento, enquanto o defumado aumentou sutilmente os valores de $\mathrm{pH}$, o filé in natura teve uma redução de $\mathrm{pH}$ nos primeiros 15 dias de armazenamento e depois este valor subiu para 6,2 (Figura 2).

$\mathrm{O}$ valor do $\mathrm{pH}$ de um alimento é importante devido à sua influência na palatabilidade e desenvolvimento de microrganismos, segundo Terra (1988), o pH de 5,8 a 6,2 indica que a carne está aceitável para o consumo, pH de 6,4 mostra que a carne é recomendada apenas para o consumo imediato e pH acima de 6,4 indica que a carne está em início de decomposição, neste estudo os valores mantiveram-se dentro do aceitável para o consumo.

\section{Colorimetria}

A colorimetria dos filés pigmentados e defumados revelou que a utilização dos corantes naturais influenciou $(\mathrm{P}<0,05)$ 
na coloração do produto final (Tabela 1).

Tabela 1. Teste de colorimetria dos filés de tilápia defumado com corantes naturais.

\begin{tabular}{lccc}
\hline \multirow{2}{*}{ Tratamentos } & \multicolumn{2}{c}{ Cor } & $\mathrm{L}^{*}$ \\
\cline { 2 - 4 } & $\mathrm{a}^{*}$ & $\mathrm{~b}^{*}$ & $54,33 \pm 1,80^{\mathrm{ab}}$ \\
Sem Inclusão & $4,36 \pm 0,25^{\mathrm{bc}}$ & $15,12 \pm 1,08^{\mathrm{c}}$ & $57,51 \pm 0,85^{\mathrm{a}}$ \\
Açaí & $5,74 \pm 0,53^{\mathrm{b}}$ & $17,80 \pm 1,14^{\mathrm{ab}}$ & $54,96 \pm 2,5^{\mathrm{ab}}$ \\
Açafrão & $2,97 \pm 0,50^{\mathrm{c}}$ & $18,15 \pm 1,17^{\mathrm{a}}$ & $52,00 \pm 1,25^{\mathrm{b}}$ \\
Beterraba & $9,40 \pm 1,25^{\mathrm{a}}$ & $16,15 \pm 0,70^{\mathrm{b}}$ & 3,77 \\
\hline Coeficiente de variação\% & 13,20 & 8,33 & 0,018 \\
\hline Valor de P & $<0,01$ & $<0,01$ & \\
\hline
\end{tabular}

* Médias \pm desvio padrão seguidas por letras distintas na mesma coluna diferem pelo teste de Tukey (P<0,05). Fonte: Autores (2021).

A utilização dos corantes naturais influenciou na coloração dos filés, onde o tratamento com utilização de beterraba proporcionou filés mais escuro $(52,00)$ e menos brilhante comparado ao tratamento com açaí ( $\mathrm{P}<0,05)$, cuja luminosidade foi de 57,51 , porém estes não diferiram dos demais tratamentos. A coloração avermelhada foi mais acentuada $(\mathrm{P}<0,05)$ no tratamento com pó de beterraba $(9,40)$, esta coloração foi pouco insinuante no tratamento com açafrão $(2,97)$ que teve os maiores resultados $(\mathrm{p}<0,05)$ para a intensidade de coloração amarela $(18,15)$. Estes resultados reafirmam a tendência do consumidor em preferir alimentos com cores voltadas ao amarelo e vermelho, isto pode ser comprovado no teste sensorial para os filés pigmentados e defumados (Tabela 2).

De acordo com Souza et al. (2020) quando é analisado a cor dos filés, os valores de $a^{*}$ e b* aumentam em função da técnica e pigmentação aplicada na defumação. Os autores afirmam que a técnica de defumação (tempo x temperatura aplicada) influencia nesses valores, sendo menores quando a defumação é a frio (baixa temperatura por maior tempo de exposição da fumaça). Por outro, lado quando os filés são pigmentados antes da defumação, estes valores de $a^{*}$ e $b^{*}$ apresentam-se significativamente maiores que os sem pigmentação ( $a^{*}=-1,5$ e $\left.b^{*} 9,54\right)$. Resumidamente, Souza et al. (2020) afirmaram que os filés de tilápia quando são pigmentados apresentam valores de $\mathrm{a}^{*} \mathrm{e} \mathrm{b}^{*}$ significativamente maiores que os sem serem pigmentados, enquanto o processo de defumação a quente os maiores valores que os defumados pelo método a frio.

Neste experimento os valores de $a^{*}$ e $b^{*}$ variaram muito em função do tipo de corante utilizado (Tabela 1). Apenas o com açafrão foi menor para o valor de $\mathrm{a}^{*}$ em relação aos filés não pigmentados.

Em relação a luminosidade, quando os filés de tilápia são defumados pelo método a frio, a pigmentação não interfere na luminosidade, entretanto na defumação a quente, os filés não pigmentados apresentam maior luminosidade (Souza et al., 2020).

Com a perda de água no processo de defumação, segundo Fluentes et al. (2012), ocorre diminuição da luminosidade. Mas, Souza et al. (2020) complementam que filés defumados a quente, com o aumento da temperatura utilizada no processo, aumenta a perda de lipídeos, resultando em filés com superfícies com maior brilho, consequentemente com maior luminosidade que os filés defumados pelo método a frio.

\section{Análise sensorial}

Da mesma forma, no teste sensorial de aceitabilidade e intenção de compra dos filés pigmentados com corantes naturais e defumados foi possível observar que o uso dos corantes naturais influenciou $(\mathrm{p}<0,05)$ nas características sensoriais dos produtos elaborados, onde os filés de tilápia pigmentados com açafrão e beterraba em pó obtiveram maiores médias das notas atribuídas pelos avaliadores (Tabela 2). Segundo Dutcosky (2013) essas notas correspondem a gostei ligeiramente (6) a gostei muito (8). 
Tabela 2. Análise sensorial dos filés de tilápia defumados com corantes naturais.

\begin{tabular}{lccc}
\hline \multirow{2}{*}{ Tratamentos } & \multicolumn{3}{c}{ Parâmetros } \\
\cline { 2 - 4 } & Cor $^{1}$ & Aparência ou impressão global $^{1}$ & Teste de Intenção de $_{\text {Compra }^{2}}$ \\
\hline Sem Inclusão & $6,12 \pm 1,65^{\mathrm{b}}$ & $6,19 \pm 1,90^{\mathrm{b}}$ & $3,72 \pm 1,55^{\mathrm{c}}$ \\
Açaí & $6,52 \pm 1,79^{\mathrm{b}}$ & $6,21 \pm 1,25^{\mathrm{b}}$ & $4,09 \pm 1,38^{\mathrm{b}}$ \\
Açafrão & $8,24 \pm 1,34^{\mathrm{a}}$ & $8,10 \pm 1,21^{\mathrm{a}}$ & $4,57 \pm 1,12^{\mathrm{a}}$ \\
Beterraba & $8,07 \pm 1,27^{\mathrm{a}}$ & $7,97 \pm 1,74^{\mathrm{a}}$ & $4,49 \pm 1,94^{\mathrm{a}}$ \\
\hline
\end{tabular}

Médias \pm desvio padrão seguidas por letras distintas na mesma coluna diferem pelo teste de Tukey $(\mathrm{P}<0,05)$. ${ }^{1}$ Escala hedônica entre 1 (desgostei muitíssimo) e 9 (gostei muitíssimo. ${ }^{2}$ Escala hedônica entre 1 (certamente não compraria) e 5 (certamente compraria). Fonte: Autores (2021).

Os resultados obtidos pelos testes sensoriais corroboram com o observado no teste de colorimetria. De certo, a preferência dos provadores pelos filés pigmentados com açafrão e beterraba em pó seja devido ao aspecto visual proporcionado, pois conforme Franco (2003), o emprego de pigmentos naturais ou artificiais na salmoura pré-defumação pode proporcionar coloração mais atraente ao produto, além da coloração peculiar ocasionada pelo processo de defumação.

Quanto à intenção de compra dos filés pigmentados e defumados com corantes naturais apresentaram significativamente as maiores notas, sendo que provavelmente comprariam os filés quando utilizado o corante açaí e certamente compraria quando com os corantes açafrão e beterraba, segundo a classificação dos cinco pontos pela escala hedônica segundo Meilgaard (1999) e Damásio e Silva (1996), considerando o arredondamento das notas apresentadas pelos avaliadores (Tabela 2).

Neste experimento os valores médios das notas atribuídas pelos provadores para os filés defumados foram semelhantes (quando arredondadas) aos relatados por Santos et al. (2007). Os autores mencionaram que os valores variaram de 2,54 a 2,86, porém utilizaram dados transformados $(y=\sqrt{ } x+0,5)$.

\section{Composição centesimal}

A inclusão de corantes naturais na salmouragem pré-defumação influenciou $(\mathrm{P}<0,05)$ na composição centesimal dos filés defumados em relação a umidade, lipídios e cinzas (Tabela 3). Houve diferença significativa umidade, lipídeos e as cinzas dos filés de tilápia pigmentados e defumados, porém não foi possível verificar diferença significativa para a proteína bruta, cujo valor médio foi de $23,23 \%$.

Tabela 3. Composição centesimal dos filés defumados com corantes naturais.

\begin{tabular}{lcccc}
\hline Tratamentos & $\begin{array}{c}\text { Umidade } \\
(\%)\end{array}$ & Proteína bruta $(\%)$ & $\begin{array}{c}\text { Lipídios } \\
(\%)\end{array}$ & $\begin{array}{c}\text { Cinzas } \\
(\%)\end{array}$ \\
\hline Sem Inclusão & $69,65 \pm 1,99^{\mathrm{a}}$ & $23,33 \pm 1,56$ & $2,30 \pm 0,45^{\mathrm{b}}$ & $5,05 \pm 0,75^{\mathrm{a}}$ \\
Açaí & $68,55 \pm 0,75^{\mathrm{b}}$ & $23,72 \pm 1,98$ & $4,02 \pm 1,01^{\mathrm{a}}$ & $4,10 \pm 0,22^{\mathrm{b}}$ \\
Açafrão & $68,48 \pm 0,99^{\mathrm{b}}$ & $22,44 \pm 1,79$ & $2,70 \pm 0,67^{\mathrm{b}}$ & $5,49 \pm 0,87^{\mathrm{a}}$ \\
Beterraba & $68,40 \pm 1,05^{\mathrm{b}}$ & $23,43 \pm 1,21$ & $3,35 \pm 1,29^{\mathrm{a}}$ & $4,81 \pm 0,92^{\mathrm{a}}$ \\
\hline Valor de P & $<0,0001$ & $>0,05$ & $<0,0001$ & $<0,0001$ \\
\hline Coeficiente de variação $(\%)$ & 5,66 & 4,63 & 7,23 & 4,67 \\
\hline
\end{tabular}

Médias \pm desvio padrão seguidas por letras distintas na mesma coluna diferem pelo teste de Tukey $(\mathrm{P}<0,05)$. Fonte: Autores (2021).

Neste estudo, observou-se uma menor umidade no tratamento controle, em relação aos demais. No teor de lipídeos, a inclusão dos corantes de açaí e beterraba proporcionaram maior teor de lipídeos nos filés defumados, enquanto o açaí proporcionou menor teor de cinzas. Contrariamente ao observado neste estudo em relação à umidade, Franco et al. (2013) observou que a utilização de pigmentos atuou como uma película de proteção nos filés proporcionando menor perda de água. 
Em geral, os teores de umidade, proteína bruta e lipídios encontrados neste estudo são inferiores ao relatados por Souza et al. (2004), certamente devido ao tempo inferior (90 minutos) pelo qual os filés foram submetidos ao processo de defumação comparando aos 240 minutos utilizados para defumação dos filés de acordo com Souza et al. (2004).

Além de serem pigmentos, os produtos utilizados, também possuem propriedades antioxidantes, o que é muito importante para a manutenção das características sensoriais e nutricionais dos alimentos. Como é o caso do alecrim que possui vários compostos fenólicos como o carnosol, rosmanol, romaridifenol e romariquinona. O açafrão possui curcuminas demetoxiladas (Rohaeti et al., 2014), e o açaí possuem compostos fenólicos e antocianinas, todos estes compostos são conhecidos por possuírem potente atividade antioxidante (Cedrim et al., 2018). O açaí, de acordo com Cesar et al. (2014), apresenta maior poder antioxidante, quando comparado com frutos ricos em antocianina, com mirtilos e amoras. Segundo os autores a cianidina3-glucosídeo (1040 mg/L de polpa) era a antocianina em maior quantidade na polpa de açaí. Devido ao alto teor dos polifenóis, presente no açaí, ele é considerado uma das cinco frutas com maior potencial antioxidante, com diversas propriedades, desde anti-inflamatória e farmacológica (Kang et al., 2010).

Embora, não se conheçam muito profundamente as propriedades antioxidantes da beterraba, ela assim como a batata e os brócolis inibem a oxidação de frações de lipoproteínas de baixa densidade (LDL) e lipoproteínas de densidade muito baixa (VLDL) (Food Ingredients Brasil, 2009).

\section{Oxidação lipídica}

De acordo com os resultados da análise de substâncias reativas ao ácido tiobarbitúrico (TBARs), pode-se observar que o processo de defumação promoveu uma pré-oxidação dos filés defumados comparados aos do filé fresco in natura. Observandose um valor médio $(\mathrm{P}>0,05)$ entre os tratamentos de $0,27 \mathrm{mg} \mathrm{MDA} / \mathrm{kg}$ de filé logo ao término do processo de defumação (tempo 0) (Figura 3).

De maneira geral, a oxidação dos filés pigmentados e defumados se mantiveram estáveis ao longo do período de armazenamento, mantendo valores médios de 0,27, 0,29 e 0,28 mg de MDA/kg, demonstrando que estes são bons antioxidantes. Enquanto, que a oxidação dos filés in natura teve um aumento linear $(\mathrm{y}=-0,12+0,095 \mathrm{x} ; \mathrm{R} 2=0,82)$, indicando maior instabilidade das reações oxidativas (Figura 3).

Independente dos tratamentos, os níveis de TBARs indicam a presença reduzida de malonaldeídos durante o período de avaliação, pois os valores de TBARs obtidos são inferiores ao considerado prejudicial a saúde do consumidor, que seria de 160 mg MDA/kg (Terra et al., 2006). Porém, segundo Ogawa e Maia (1999), valores acima de $2 \mathrm{mg}$ de malonaldeído/kg, já são suficientes para o peixe apresentar odor e sabor característico de ranço.

Os valores de TBARs obtidos no presente estudo são inferiores aos obtidos por Aiura et al. (2008), que ao trabalharem com conservação de filés de tilápia salgado, encontraram valores mínimos de 0,50 mg de MDA/kg e máximos de 3,60 mg de MDA/kg de peixe. 
Figura 3. Análise de TBARs de filés de tilápia defumados com diferentes corantes naturais e filés in natura durante 30 dias de armazenamento sob refrigeração.

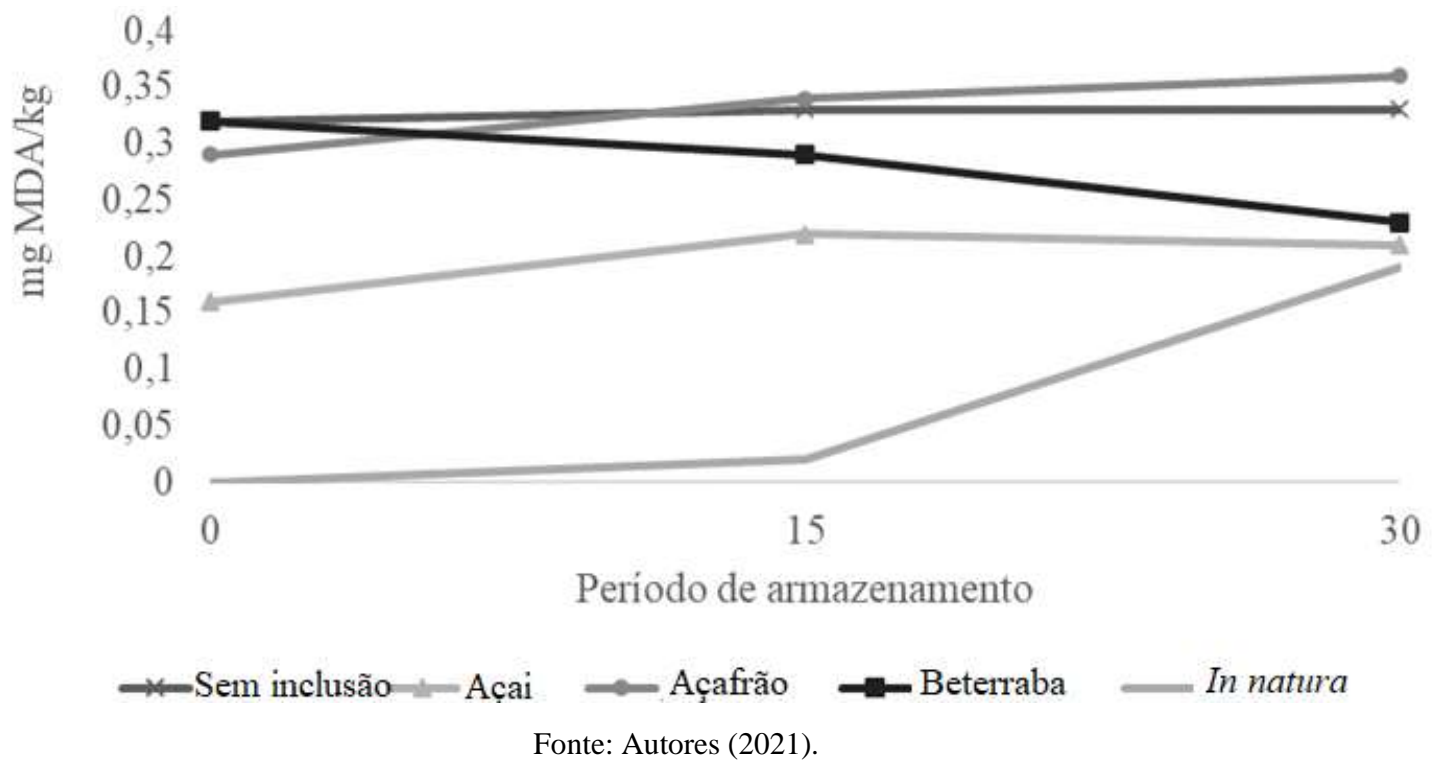

Embora o alecrim e outras especiarias como o açafrão e até mesmo frutos como o açaí tenham propriedades antioxidantes os trabalhos divergem sobre este efeito. Por exemplo, Larosa et al. (2012) ao avaliarem o efeito antioxidante do orégano, alecrim, sálvia e moringa na conservação de carne mecanicamente separada (CMS) de tilápia (Oreochromis niloticus), concluíram maior efeito antioxidante da sálvia na CMS de tilápia durante 120 dias de armazenagem a $-18^{\circ} \mathrm{C}$. Em outro estudo, o alecrim mostrou-se eficiente em relação ao suco de cebola na conservação da CMS de sardinha (Sardina pilchardus) durante cinco meses de armazenagem a $-18{ }^{\circ} \mathrm{C}$ (Serdaroğlu \& Felekoğlu, 2005). Em filés salgados de tilápia, houve um efeito protetor do alecrim (Afonso \& Sant'Ana, 2008). Porém, segundo Fogaça et al. (2014) a adição de alecrim à salmoura antes da defumação, até o nível de $1,6 \%$, não é eficiente no controle da oxidação lipídica em filés de tambaqui.

\section{Conclusão}

A utilização de corantes naturais durante a salga para defumação de filés de tilápia mostrou-se eficiente para a constituição da cor dos filés, melhorando sua aparência refletida pela maior preferência. Além disso, também influenciou positivamente na manutenção da oxidação dos filés durante o período de 30 dias de armazenamento sob refrigeração. O uso dos corantes proporciona uma diminuição na umidade dos filés defumados, impactando em aumento nos teores de lipídeos e cinzas.

Novos estudos avaliando o potencial antioxidante destes corantes naturais são recomendados, através de outras técnicas de análises antioxidantes, considerando também análises durante o tempo de armazenamento e testes com diferentes concentrações destes compostos naturais.

\section{Referências}

Afonso, M. S., \& Sant'Ana, L. S. (2008). Effects of pretreatment with rosemary (Rosmarinus officinalis L.) in the prevention of lipid oxidation in salted tilapia fillets. Journal of food quality, 31(5), 586-595.

Aiura, F. S., Carvalho, M. R. B., Viegas, E. M. M., Kirschnik, P. G., \& Lima, T. M. A. (2008). Conservação de filés de tilápia-do-nilo (Oreochromis niloticus) em salga seca e salga úmida. Arquivo Brasileiro de Medicina Veterinária e Zootecnia, 60, 1531-1537.

American Public Health Association (APHA). (1992). Committe on Microbiologycal Methods for Foods. Compendiun of Methods for the Microbiologycal Examination of Foods. APHA. 129p.

AOAC. Official methods of analysis of the AOAC (2005). In: AOAC -Association of Official Analytical Chemists, (18th ed,). AOAC 
Assis, M. F., Franco, M. L. R. S., Stéfani, M. V., Franco, N. P., Godoy, L. C., Oliveira, A. C., \& Hoch, A. L. V. (2009). Efeito do alecrim na defumação da carne de rã (Rana catesbeiana): características sensoriais, composição e rendimento. Food Science and Technology, 29, 553-556.

Bligh, E. G., \& Dyer, W. J. (1959). A rapid method of total lipid extraction and purification. CanadianJ ournal of Biochemistry and Physiology, $37,911-917$.

Brasil. (2019). Ministério da Saúde. Agência Nacional de Vigilância Sanitária. Instrução normativa n ${ }^{\circ} 60$, de 23 de dezembro de 2019 . Estabelece as listas de padrões microbiológicos para alimentos. https://www.in.gov.br/en/web/dou/-/instrucao-normativa-n-60-de-23-de-dezembro-de-2019-235332356

Damásio, M. H., \& Silva, M. A. A. P. (1996). Curso de treinamento em análise sensorial. Apostila. Campinas: fundação tropical de tecnologia" André Tosello.

Dutcosky, S. D. (2013). Análise sensorial de alimentos, (4a ed.), Champagnat.

Food and Agriculture Organization -FAO. (2018). The State of World Fisheries and Aquaculture 2018 -Meeting the sustainable development goals. Rome: Licence CC BY-NC-SA 3.0 IGO.

Franco, M. L. R. S. (2003). Processamento do filé e da pele de tilápia do Nilo: aspectos tecnológicos, composição centesimal, rendimento, vida útil e teste de resistência da pele curtida. Jaboticabal Tese de Doutorado. (Centro de Aquicultura da UNESP), Universidade Estadual Paulista.

Franco, M. L. R. S., Viegas, E. M. M., Kronka, S. N., Vidotti, R. M., Assano, M., \& Gasparino, E. (2010). Effects of hot and cold smoking processes on organoleptic properties, yield and composition of matrinxa fillet. Revista Brasileira de Zootecnia, 39, 695-700.

Franco, M. L. R. S., Amaral, L. A. D., Viegas, E. M. M., Kronka, S. D. N., Gasparino, E., Mikcha, J. M. G., \& Del Vesco, A. P. (2013). Qualidade microbiológica e vida útil de filés defumados de tilápia-do-nilo sob refrigeração ou congelamento. Pesquisa Agropecuária Brasileira, 48, $1071-1079$.

Galvão, J., Oetterer, M. (2014). Qualidade e processamento de pescado. Elsevier, 237 p.

Gava, A. Tecnologia de alimentos: princípios de tecnologia de alimentos. Nobel, 2008.

Gonçalves, A. A. Tecnologia do Pescado: Ciência, Tecnologia, Inovação E Legislação. Atheneu, 2011.

Instituto Adolfo Lutz. (2005). Métodos químicos e físicos para análise de alimentos, (4a ed.), Editora MS.

Jensen, C., Birk, E., Jokumsen, A., Skibsted, L. H., \& Bertelsen, G. (1998). Effect of dietary levels of fat, $\alpha$-tocopherol and astaxanthin on colour and lipid oxidation during storage of frozen rainbow trout (Oncorhynchus mykiss) and during chill storage of smoked trout. Zeitschrift für Lebensmitteluntersuchung undForschung A, 207(3), 189-196.

Juncher, D., Rønn, B., Mortensen, E., Henckel, P., Karlsson, A., Skibsted, L., \& Bertelsen, G. (2001). Effect of pre-slaughter physiological conditions on the oxidative stability of colour and lipid during chill storage of pork. Meat science, 58(4), 347-357.

Justen, A. P., Souza, M. L. R., Monteiro, A. R., Mikcha, J. M., Gasparino, E., Delbem, Á. B., Carvalho, M. R. B., \& Del Vesco, A. P. (2017). Preparation of extruded snacks with flavored flour obtained from the carcasses of Nile tilapia: physicochemical, sensory, and microbiological analysis. Journal of Aquatic Food Product Technology, 26, 258-266.

Kang, J., Li, Z., Wu, T., Jensen, G. S., Schauss, A. G., Wu, X. (2010). Anti-oxidant capacities of flavonoid compounds isolated from acai pulp (Euterpe oleracea Mart.). Food Chemistry, 122(3), 610-617.

Larosa, G., Vidotti, R., Alves, V., Lima, T. M. A., \& Carvalho, M. (2012). Elaboração de produto cárneo de tilápia com antioxidantes visando sua utilização como recheio ou acompanhamento da refeição. Alimentos e Nutrição, 23 (4), 609-617.

Meilgaard, M., Civille, G.V., \& Carr, B. T. (1999). Sensory Evaluation Techniques. CRC Press.

Ogawa, M., \& Maia, E. (1999). Características específicas do pescado. Manual de pesca ciência e tecnologia do pescado. Varela. São Paulo, 9-15.

Pereira, S. A., Shitsuka, D. M., Parreira, F. J. \& Shitsuka, R. (2018). Metodologia da pesquisa científica. UFSM.

Rohaeti, E., Rafi, M., Syafitri, U. D., Herianto, R. (2014). Fourier transform infrared spectroscopy combined with chemometrics for descrimination of Curcuma longa, Curcuma xanthorriza and Zingiber cassumar. Elsevier B. V. 1386-1425.

Santos, L. D. D., Zara, R. F., Visentainer, J. V., Matsushita, M., Souza, N. E. D., \& Franco, M. L. R. D. S. (2007). Avaliação sensorial e rendimento de filés defumados de tilápia (Oreochromis niloticus Linnaeus, 1757) na presença de alecrim (Rosmarinus officinalis). Ciência e Agrotecnologia, 31 , $406-412$.

SAS Institute (Cary, USA). (2010). SAS/STAT User"es guide, version 6. (4a ed.), Cary. 1, 943.

Serdaroğlu, M., \& Felekoğlu, E. (2005). Effects of using rosemary extract and onion juice on oxidative stability of sardine (Sardina pilchardus) mince. Journal of Food Quality, 28(2), 109-120.

Silva, D. J., \& Queiroz, A. C. (2002). Análise de alimentos: métodos químicos e biológicos. (3a ed.), UFV.

Souza, M. L. R. D., Baccarin, A. E., Viegas, E. M. M., \& Kronka, S. D. N. (2004). Defumação da tilápia do Nilo (Oreochromis niloticus) inteira eviscerada e filé: aspectos referentes às características organolépticas, composição centesimal e perdas ocorridas no processamento. Revista Brasileira de Zootecnia, 33, 2736.

Souza, M. L. R., Viegas, E. M. M., Kronka, S. N., Amaral, L. A., Parisi, G., Coradini, M. F., \& Goes, E. S. R. (2020). Cold and hot smoked nile tilapia fillets: quality and yield of pigmented and unpigmented fillets. Italian Journal of Food Science, 32(2), 450-465.

Terra, N. N. (1988). Carne e seus derivados: tecn. de controle de qualidade. NBL editora. 
Research, Society and Development, v. 10, n. 13, e79101320464, 2021

(CC BY 4.0) | ISSN 2525-3409 | DOI: http://dx.doi.org/10.33448/rsd-v10i13.20464

Terra, R. A., Cichoski, A. J. \& Freitas, R. J. S. (2006). Valores de nitrito e TBARS durante o processamento e armazenamento da paleta suína curada, maturada e fermentada. Ciência Rural, 36(3), 965-970

Tilami, S. K., \& Sampels, S. (2018). Nutritional value of fish: lipids, proteins, vitamins, and minerals. Reviews in Fisheries Science \& Aquaculture, 26(2), 243253.

Vanz, A. (2013). Avaliação do potencial antioxidante de extrato de alecrim na preservação de filés de tilápia do nilo defumados. Trabalho de Conclusão de Curso (Tecnólogo em Alimentos). Universidade Tecnológica Federal do Paraná. 